\title{
Changing perspectives in biobank research: from individual rights to concerns about public health regarding the return of results
}

\author{
Joanna Stjernschantz Forsberg ${ }^{\star, 1}$, Mats G Hansson ${ }^{1}$ and Stefan Eriksson ${ }^{1}$ \\ ${ }^{1}$ Centre for Research Ethics and Bioethics, Uppsala University, Uppsala, Sweden
}

During the past decade, various guidelines that imply a duty for researchers to disclose information obtained through research to participants have emerged. The character and extent of this obligation have been debated extensively, with much attention devoted to the decisiveness of the validity and utility of the results in question. The aim of this paper is to argue that individual results from research on materials stored in large-scale biobanks, consisting of samples taken within the healthcare system or of altruistically donated materials, should not be returned. We will defend the thesis that medical research on these biobanks should be viewed as a collective project to improve public health, and that available resources should be utilized to pursue this goal. We argue that there is a need for a change of perspectives. Medical research should not primarily be viewed as a danger that individuals must be protected from, but rather be recognized as constituting a necessary defense against current and future diseases. Research that bears the prospect of advancing medicine and that can be carried out at no risk to individuals should be endorsed and facilitated. This calls for a shift of focus from autonomy and individual rights toward collective responsibility and solidarity.

European Journal of Human Genetics (2009) 17, 1544-1549; doi:10.1038/ejhg.2009.87; published online 27 May 2009

Keywords: biobanks; returning results; solidarity; public health; altruism

\section{Introduction}

Biobanks offer a great possibility to promote health and wellbeing. Millions of previously collected tissue samples are stored throughout the world, ready to be used for individual health care, teaching, quality control and research. These collections of biological materials have been assembled in numerous ways and for diverse reasons, ranging from retained materials taken for diagnostic or therapeutic purposes within the healthcare system to samples obtained through voluntary participation in

${ }^{*}$ Correspondence: Dr J Stjernschantz Forsberg, Centre for Research Ethics and Bioethics, Uppsala University, Uppsala Science Park, Dag Hammarskjoldsv. 14B, 75185 Uppsala, Sweden.

Tel: + 4618 6113520; Fax: + 4618 506404;

E-mail: joanna.forsberg@crb.uu.se

Received 23 September 2008; revised 2 April 2009; accepted 15 April 2009; published online 27 May 2009 research projects. Until lately, many of the samples obtained in clinical settings were stored and used for research without the informed consent, and sometimes knowledge, of the individual 'donors'.

Recent advances in medicine, in particular in the field of genetics, have increased the usability of materials stored in biobanks. DNA can be obtained from blood, exfoliated cells, frozen tissue samples and formalin-fixed blocks. ${ }^{1}$ Many countries have extensive population-based screening programs for newborns and dried blood spots are often stored for future use. Such spots are suitable for genetic epidemiological studies and DNA has been successfully extracted from 25 -year-old samples. ${ }^{2,3}$ These advances have added to the ongoing ethical debate on the conditions for participation in biobank research. A common approach for sorting out the ethical aspects of such research has been to focus on individual rights, for 
example, to demand specific consent for all use of donated human tissue samples ${ }^{4,5}$ or to request compensation ${ }^{6,7}$ such as free health examinations or the return of individual results. However, in all medical research one needs to weigh individual rights against public health concerns. In our research team we have previously suggested that when risks for individuals are small, that is, when using coded or anonymous tissue samples and personal data, general research interests may override concerns about individual rights. ${ }^{8-10}$ In practice this approach implies that previously collected samples may, under certain conditions, be used even when no consent is available and that new biobanks can be established on the basis of broad consent for future unspecified biomedical research. In this article we will investigate what a public health approach may imply for another contested issue, that of returning individual results to the sources of the samples. Various guidelines have emerged during the past decade implying an obligation for researchers to return results. ${ }^{11,12}$ As Miller et al ${ }^{13}$ have pointed out, a considerable amount of confusion exists concerning the extent and character of this putative duty.

\section{The context of the debate}

The debate on returning results to participants has spanned from recommending disclosure of more or less all requested information obtained through clinical research (based on respect for persons and not treating individuals as a means to an end) by Shalowitz and Miller ${ }^{14}$ to the more restrictive approach of Beskow et al ${ }^{15}$ according to which results from population-based research involving genetics should not be returned if they are not expected to be clinically relevant. Ravitsky and Wilfond ${ }^{16}$ have proposed a result evaluation approach, according to which the nature of the generated information (the analytical validity and the clinical utility) and the context of the study (influencing the investigators' capabilities for appropriate disclosure, the subjects' alternative access to the information and the relationship between the investigator and the subject) should be considered when determining if information should be returned. They state that: 'For example, an epidemiologic study of samples that entails no personal contact with participants attenuates justifications to directly communicate results that do not exceed a high threshold of utility'. This has been opposed by several commentators, ${ }^{17-20}$ arguing that the relationship between the researcher and the subject should not be of relevance when considering if a specific result should be disclosed. According to this view justice requires that the same results be treated in the same way regardless of the relational factor. The approach of Ravitsky and Wilfond has also been argued to perpetuate the therapeutic misconception. ${ }^{20-22}$ Kristman and Kreiger ${ }^{23}$ have recently suggested a different method for deciding if information should be disclosed in the context of population-based genetic research, relying on the principles of autonomy, nonmaleficence and beneficence. According to this principle-based framework, each case should be analyzed independently, weighing the different principles against each other. It has also been proposed that researchers have a duty to recontact individuals that have participated in research when new knowledge is attained that alters the significance of previous results. $^{24}$

All of these approaches imply that individuals sometimes have a right to results obtained through medical research, that it is quite legitimate to wonder: 'What's in it for me?' when asked to participate. In the following sections we will argue that results from ethically approved research using large-scale biobanks should not be returned, and that the important distinction between research and clinical care provides justification as to why resources that could be used for returning results instead should be used solely for research. For the purpose of this article, all information obtained through research, both anticipated results and incidental findings will be denoted 'results' and no distinctions will be made based on validity or clinical significance.

We will first put the current debate into perspective by suggesting that medical research should, in general, not be regarded as something intrinsically dangerous, but rather as constituting the major available means for protection against current and future disease. This change of perspectives implies an emphasis on collective responsibility and solidarity in addition to the individual rights of citizens.

\section{Healthcare cannot be taken for granted: a change of perspectives}

As members of high-tech societies, it seems that we have come to take healthcare too much for granted. Modern people tend to live under the false assumption that they are safe from the kinds of threats to their health that previously killed and injured many. Even if the possibility of emerging new diseases, or old diseases rendered untreatable, is acknowledged, one somehow seems to believe that the human level of sophistication will provide protection. That the healthcare system is a product of much previous research and experience, without which there would be no healthcare, is often ignored, as is the realization that medical research is a slow process that cannot be expected to be of direct use if initiated only once the need is evident to all. Healthcare and medical research offer a chance to keep up with the evolution of new and old diseases. Even in the absence of such evolution, people die and suffer of diseases for which there is no cure or treatment today. Advances in healthcare require medical research which in turn requires the cooperation of individuals. ${ }^{25}$

Contrary to most medical research, biobank research offers a possibility to promote health and wellbeing at no individual cost or risk (if confidentiality is protected and 
potential negative effects on groups of people are obviated). Thus, given the need for advances in medicine, research of this sort should be endorsed and facilitated and resources should be allocated to achieving as much public gain as possible. The distinction between healthcare and research should be made clear, so that individuals do not assume direct personal benefit from research but rather recognize the privilege of having a chance to contribute to the advancement of public health. Medical research using large-scale biobanks with coded samples should be thought of as a collective project, as an attempt to solve a puzzle in which every sample is an equally important piece. The pieces are not studied individually for personal benefit, but are put together to create a picture, like medical registers are used to produce statistics and not individual information.

This kind of research has a duty to respect the contribution of individuals by assuring them confidentiality and by producing as much medical advancement as possible. To produce and return individual results, on the other hand, is the responsibility of healthcare.

\section{The definition of research and the therapeutic misconception}

Central aspects, when discussing a possible duty to return information obtained in research, include the questions of what research is and what it is not, and what the difference between research and clinical care amounts to. The CIOMS Ethical Guidelines for Biomedical Research Involving $\mathrm{Hu}-$ man Subjects ${ }^{26}$ defines research as: 'a class of activity designed to develop or contribute to generalizable knowledge. Generalizable knowledge consists of theories, principles or relationships, or the accumulation of information on which they are based, that can be corroborated by accepted scientific methods of observation and inference.' Clinical care, on the other hand, exists primarily to benefit the individual patient. Thus, medical research is pursued for the public good (and thereby for the good of each individual), whereas clinical care is devoted to benefiting individuals directly. Without previous research there would be no healthcare today, and the existence of useful clinical care in the future is wholly dependent on ongoing and future research.

Not acknowledging the difference between research and clinical care is the basis of the therapeutic misconception, which is characterized by individuals wrongfully attributing research the goal (at least in part) of benefiting the research subjects individually. ${ }^{27}$ In the biobank context, returning individual results has been argued to nurture the therapeutic misconception. ${ }^{28}$

The discussion in what remains of this paper will be restricted to aspects of returning information from research involving large-scale biobanks consisting of materials (1) taken within the healthcare system (including screening projects) or (2) that have been altruistically donated. We argue that biobanks consisting of either (or both) of these two kinds of samples possess ethically relevant characteristics that distinguish them from many other types of biobanks (eg, smaller collections of samples taken from patients for the purpose of research on specific diseases), and that these differences are significant when considering whether results from research should be returned.

\section{Patients have a moral duty to contribute to future healthcare}

The samples in biobanks consisting of materials collected within the healthcare system have been taken specifically to benefit an individual. Once these materials have been used as planned, leftovers can be thrown away or used for research (materials saved for the distinct purpose of future individual benefit are not 'leftovers'). In either case the source of the sample has already benefited from it as intended, and it is not obvious that he or she legitimately can claim a right to further direct gain. On the contrary, as the individual has utilized the healthcare system, that is, the medical advances that largely result from past research on human beings, healthcare and research can (and should) maintain the right to use materials - that otherwise would be discarded - for the purpose of further progress.

By analogy, consider that teaching within the medical field is fundamentally dependent on the involvement of students in clinical practice: most patients are likely not very enthusiastic about the presence of an unknown person in the examining room, but accept it because they acknowledge that this is the way the system works. Those who don't are free riders. They rely on other patients permitting students to attend to have access to healthcare in the future.

In choosing to utilize the healthcare system, individuals evidently wish to benefit from past research (and teaching). It is difficult to believe that the same individuals would also not wish to benefit from present research (and teaching) when in need of it. Seen from this perspective, the right to healthcare comes with an obligation to 'take part' in medical research that is of no risk or cost to the individual. The researcher's right to make use of samples obtained in clinical practice comes with an obligation to make research results available to the healthcare system.

Individuals contribute to advancing healthcare by accepting that their leftover samples are used for research. In doing so, their samples become a public asset, like the general results of medical research are. A person cannot claim a right to individual results from research using his or her samples, but conversely cannot be denied access to advances in healthcare because his or her sample was not used in the specific research that brought about the healthcare advancement. Similarly, if a person knew that 
all the taxes paid by him or her had ended up in the healthcare system, the person would not be entitled to a discounted doctor's appointment (in spite of technically already having sponsored at least a part of it). He or she would, however, have the same right as every other taxpayer to benefit from all publically funded services although not actually having contributed directly to them. Public projects are carried out to benefit the public. Using public funds, that have been allocated to increase generalizable knowledge (or to provide public services for all taxpayers), to benefit specific individuals, diminishes the resources available for the originally intended purpose and constitutes, at a minimum, questionable allocation.

The existence of an obligation to 'take part' in the kind of medical research described above does not imply that there are no restrictions on the researchers' doings. This duty is applicable under the appropriate circumstances, guided by ethical committees and the law. This is a crucial aspect because a system built on solidarity is totally dependent on credibility and trust. To prevent future scandals such as those in Alder Hey ${ }^{29}$ or Tuskegee, ${ }^{30}$ the rules should be unambiguous and the responsibility to abide by them clear. Supervisory authorities should be in place and the need for audits carefully considered.

John Harris and others have argued that patients have a duty to live up to a social responsibility to participate in clinical research under certain circumstances ${ }^{31-34}$ and that participation in scientific research is a moral duty. ${ }^{35}$ We share this sentiment to some extent. At least, when research presents no risk or cost to the individual or to the group of people that the individual belongs to, we agree that there is an obligation to contribute to medical advances. This would be the case for noninvasive research that only involves the individual's personal data or previously taken samples. Such a line of reasoning motivates carrying out register research in many European countries and is equally pertinent to biobank research of the kind discussed here. Participating in medical research in this way should be viewed as a corollary to benefiting from the healthcare system (ie, previous contributions). Researchers and patients should be seen as a team, each doing their share to promote the common good of improved health. In much the same manner as the patient can presume to have access to the healthcare system when he or she needs it, the healthcare system should presume that the patient wishes to endorse medical advances, by not discarding leftover materials that can be used for research, and by devoting all available resources to promote this goal. Consequently, the healthcare system can only use the argument put forward if it is characterized by equality and accessibility - teamwork built on trust and solidarity is needed.

It is sometimes argued that sample donors have a right to compensation (eg, financial benefit or return of results) because researchers may have individual interests such as economic rewards or personal esteem vested in their research. However, although samples are necessary in biobank research they are only used as a source of data, like medical registers are used in epidemiology. Any benefit that can result from such research is a product not of the samples or registries themselves, but of the intellectual work done by the researchers. Thus, just as epidemiologists have no duty to compensate individuals whose data they use, neither do biobank researchers.

\section{Research has a duty to respect the act of altruism} When it comes to large-scale biobanks consisting of altruistically donated materials, the purpose of the donation is to enhance scientific knowledge to promote people's health. Autonomous agents have chosen to act, knowing that it will be of no direct medical benefit to them. They have no relationship with the researchers. Their donation has not been asked for on the grounds of their specific health status or any other central feature of their lives, and they could easily be replaced by other random persons in the population without impairing the quality of research.

Millions of people make donations to welfare. However praiseworthy this act of altruism is, the donation is not normally thought of to be associated with any rights. If an individual has chosen to donate money to the Red Cross, it does not follow that the Red Cross has a duty (out of respect for persons or for any other reason) to inform him or her individually about the result of the donation (or of anything else). The only moral duty the Red Cross has, from the donor's point of view, is to make sure that the donation leads to as much of the intended good as possible.

In much the same way, the research community has a duty to respect the altruism of sample donors. Failing to use altruistic donations for the intended purpose is disrespectful, whether the samples are used in an inappropriate manner (eg, for research projects that are not scientifically justified) or not used to their full potential due to wrongful allocation of resources.

Donating money to charity and donating tissue samples for research do, of course, differ in some respects, one of which is the possibility of commercial interests being involved in research. However, just as the Red Cross has an obligation to make use of its resources in a justifiable manner (eg, not allocate inappropriate amounts for internal use), the ethical aspects of competing financial interests could, and should, be considered by ethical committees. If potential donors are informed from the outset that there will be no direct personal gain from donating samples, and that individual results will not be returned, but that resources will be allocated to gaining as much general knowledge as possible, there need be no risk of individuals donating samples in the hope of personal 
benefit: People do not, after all, donate money to the Red Cross in the hopes of personal profit.

\section{Revisiting the arguments in favor of returning results}

Proponents of a duty to return results often base their line of reasoning on autonomy. It is claimed that individuals have a right to know what is known about them, so that they can lead their lives according to their life plans. Obviously, a policy of returning results may make individuals feel respected. On the other hand, returning preliminary results from ongoing epidemiological studies may jeopardize the scientific validity of the study due to changes in behavior or selective dropouts. In this case, participants may rather feel disrespected because their general research interests are less likely to be fulfilled. However, based on a duty to do good and avoid harm one may argue that at least incidental findings that are of medical significance should be communicated to donors of biobank materials. Reporting the incidental finding of a brain tumor on a MRI to an individual who has volunteered to actively participate in a research project, and is easily identifiable and accessible to the researchers, would definitely seem to be the right thing to do. Nevertheless, these are not conditions that characterize large-scale biobank research and it is not clear that results obtained from such research should be returned. As we have recently pointed out in our research team, 'disclosing individual research results of factors thought to imply risk for a population may cause unjustified concern. An odds ratio expressing risk cannot be translated into an individual prognosis. Misinterpretation can cause potential psychological, social and economic harm - especially before validation of the clinical significance of the findings. This is particularly true if no relevant treatment or prevention modality to combat the investigated risk is yet available'. ${ }^{9}$ Thus, for most people such information would be of no or questionable benefit, but it would impose a risk through hampering the research that can be done as well as potentially causing direct harm. Not returning results ensures that the public health mission is put first and that no risks are imposed on individuals. What can be expected from this kind of research is that it is beneficial to society at large although not harming those who 'contribute' by providing personal or genetic data, and that its benefits are distributed justly.

Performing large-scale biobank research with an implied duty to return individual results bears obvious resemblance to screening. Screening programs within the healthcare system, however, are rigorously controlled by guidelines stating that screening may not be undertaken if there is not a clear medical benefit that can be offered to the participants. An odds ratio expressing risk will arguably never be sufficient reason to start a screening program. Consider the example of hereditary hemochromatosis. Proponents of a duty to return results might find it both appropriate and necessary to report the existence of data indicating this condition to an individual, as the disease is potentially serious but can be treated if diagnosed. However, although it would be possible, there is no general screening for hemochromatosis within the healthcare system. In part this is due to ethical considerations regarding disclosing information of uncertain significance (not all homozygous individuals develop clinical disease). ${ }^{36}$ Insisting that researchers have a duty to report such results implies that they must disregard the principles and guidelines that apply to screening in healthcare, and that have been established to protect both individuals and the public good. $^{37}$

\section{Conclusion}

The purpose of medical research is to benefit the public by increasing knowledge that can be used to improve health and prevent disease, whereas the purpose of clinical care is to make use of advances gained through research to promote the health of individuals. Individuals that have utilized the healthcare system have taken advantage of previous research and can be assumed to wish to benefit from future advances. Using leftover samples for research that has been ethically approved, and not allocating resources to return individual results, respects these individuals as contributing members of the public and increases all citizens' chances of benefiting from healthcare in the future. This kind of research does not come with a duty of beneficence toward specific individuals, only an obligation to assure confidentiality and produce as much useful generalizable knowledge as possible. Returning results jeopardizes both of these aspects.

The suggestions that patients have a duty to contribute to healthcare (by accepting that leftover tissue samples are used explicitly for research), and that altruism should be respected (by allocating available resources to promote the purpose of the donation), provide a perspective that offers a possibility to advance healthcare at a cost that should be acceptable to all. With millions of people suffering from common incurable diseases and with the constant threat of the development of new ones, healthcare cannot be taken for granted. Under these circumstances it should be recognized that all individuals have an obligation out of solidarity not to hinder potentially beneficial medical research that costs them nothing and is of no risk to them. Returning individual results fails to respect the premises under which the public health project of largescale biobank research is undertaken and inevitably reduces the prospect of achieving advances by consuming resources that should be allocated to benefiting the public good. Principally, results should therefore not be returned. 


\section{Acknowledgements}

The research for this publication was supported by the EU sixth framework programmes AutoCure and CCPRB, and by Pfizer's Research Foundation. The funders had no role in the research process and the publication reflects only the authors' views. The funders are not liable for any use that may be made of the information herein. We also thank Gert Helgesson for initial helpful suggestions.

\section{References}

1 Santella RM: Approaches to DNA/RNA extraction and whole genome amplification. Cancer Epidemiol Biomarkers Prev 2006; 15: $1585-1587$.

2 Sjöholm MI, Dillner J, Carlson J: Assessing quality and functionality of DNA from fresh and archival dried blood spots and recommendations for quality control guidelines. Clin Chem 2007; 53: $1401-1407$.

3 Hannelius U, Lindgren CM, Melén E, Malmberg A, von Dobeln U, Kere J: Phenylketonuria screening registry as a resource for population genetic studies. J Med Genet 2005; 42: e60.

4 Arnason V: Coding and consent: moral challenges of the database project in Iceland. Bioethics 2004; 18: 27-49.

5 Caulfield T: Biobanks and blanket consent: the proper place of the public good and public perception rationales. Kings Law J 2007; 18: 209-226.

6 Marchant GE: Property rights and benefit-sharing for DNA donors? Jurimetrics 2005; 45: 153-178.

7 Merz JF, Magnus D, Cho MK, Caplan AL: Protecting subjects' interests in genetics research. Am J Hum Gen 2002; 70: 965-971.

8 Hansson MG, Dillner J, Bartram CR, Carlson JA, Helgesson G: Should donors be allowed to give broad consent to future biobank research? Lancet Oncol 2006; 7: 266-269.

9 Helgesson G, Dillner J, Carlson J, Bartram CR, Hansson MG: Ethical framework for previously collected biobank samples. Nat Biotechnol 2007; 25: 973-976.

10 Hansson MG: Ethics and biobanks. Br J Cancer 2009; 100: 8-12.

11 Knoppers BM, Joly Y, Simard J, Durocher F: The emerge of an ethical duty to disclose genetic research results: international perspectives. Eur J Hum Genet 2006; 14: 1170-1178.

12 Quiad KA, Jessup NM, Meslin EM: Disclosure of genetic information obtained through research. Genet Test 2004; 8: 347-355.

13 Miller FA, Christensen R, Giacomini M, Robert JS: Duty to disclose what? Querying the putative obligation to return research results to participants. J Med Ethics 2008; 34: 210-213.

14 Schalowitz DI, Miller FG: Disclosing individual results of clinical research, implications of respect for participants. JAMA 2005; 294: 737-740.

15 Beskow LM, Burke W, Merz JF et al: Informed consent for population-based research involving genetics. JAMA 2001; 286: $2315-2321$.

16 Ravitsky V, Wilfond BS: Disclosing individual genetic results to research participants. Am J Bioeth 2006; 6: 8-17.
17 Fernandez CV, Weijer C: Obligations in offering to disclose genetic research results. Am J Bioeth 2006; 6: 44-46.

18 Fryer-Edwards K, Fullerton SM: Relationships with test-tubes: where's the reciprocity? Am J Bioeth 2006; 6: 36-38.

19 Dressler LG, Juengst ET: Theresholds and boundaries in the disclosure of individual genetic research results. Am J Bioeth 2006; 6: $18-20$.

20 Meltzer LA: Undesirable implications of disclosing individual genetic results to research participants. Am J Bioeth 2006; 6: $28-30$.

21 Parker LS: Best laid plans for offering results go awry. Am J Bioeth 2006; 6: $22-23$

22 Ossorio PN: Letting the gene out of the bottle: a comment on returning individual research results to participants. Am J Bioeth 2006; 6: 24-25.

23 Kristman VL, Kreiger N: Information disclosure in populationbased research involving genetics: a framework for the practise of ethics in epidemiology. Ann Epidemiol 2008; 18: 335-341.

24 Wade $\mathrm{CH}$, Kalfoglou AL: When do genetic researchers have a duty to recontact study participants? Am J Bioeth 2006; 6: $26-27$.

25 Hansson MG: For the safety and benefit of current and future patients. Pathobiology 2007; 74: 198-205.

26 Council for International Organizations of Medical Sciences: International Ethical Guidelines for Biomedical Research Involving Human Subjects. Geneva: CIOMS, 2002.

27 Henderson GE, Churchill LR, Davis AM et al: Clinical trials and medical care: defining the therapeutic misconception. PLoS Med 2007; 4: e324.

28 Clayton EW, Ross LF: Implications of disclosing individual results of clinical research. JAMA 2006; 295: 37.

29 Bauchner H, Vinci R: What have we learnt from the Alder Hey affair? BMJ 2001; 322: 309-310.

30 Reverby SM: Tuskegee: could it happen again? Postgrad Med J 2001; 77: 553-554.

31 Evans HM: Should patients be allowed to veto their participation in clinical research? J Med Ethics 2004; 30: 198-203.

32 Evans HM: Do patients have duties? J Med Ethics 2007; 33: 689-694.

33 Rhodes R: Rethinking research ethics. Am J Bioeth 2005; 5: $7-28$.

34 Chadwick R, Berg K: Solidarity and equity: new ethical frameworks for genetic databases. Nat Rev Genet 2001; 2: 318-321.

35 Harris J: Scientific research is a moral duty. J Med Ethics 2005; 31: $242-248$.

36 Whitlock EP, Garlitz BA, Harris EL, Beil TL, Smith PR: Screening for hereditary hemochromatosis: a systematic review for the U.S. Preventive Services Task Force. Ann Intern Med 2006; 145: 209-223.

37 Andermann A, Blancquaert I, Beauchamp S, Déry V: Revisiting Wilson and Jungner in the genomic age: a review of screening criteria over the past 40 years. Bull World Health Organ 2008; 86: $317-319$. 